\title{
PROPOSTA DE METODOLOGIA PARA INSPEÇÕES CADASTRAIS E ROTINEIRAS DE OBRAS DE ARTE ESPECIAIS DE PEQUENO E MÉDIO PORTE
}

\author{
SANTOS, LORENA VIEIRA DOS \\ Graduanda em Engenharia Civil \\ Universidade do Estado de Minas Gerais \\ Minas Gerais, Brasil \\ lorena.vieirasts@hotmail.com
}

\author{
SILVA JÚNIOR, LADIR ANTÔNIO DA \\ Mestre em Engenharia Civil \\ Universidade do Estado de Minas Gerais \\ Minas Gerais, Brasil \\ ladir@hotmail.com
}

\author{
COELHO, ANA ELISA BRAZ \\ Graduanda em Engenharia Civil \\ Universidade do Estado de Minas Gerais \\ Minas Gerais, Brasil \\ anaelisabrazcoelho@gmail.com
}

\author{
SOUZA, WAGNER CAVALARE DE \\ Mestre em Engenharia Civil \\ Universidade do Estado de Minas Gerais \\ Minas Gerais, Brasil \\ wcavalare2005@yahoo.com.br
}

\section{RESUMO}

As pontes, também conhecidas como Obras de Arte Especiais (OAE), são estruturas que compõem o sistema viário e sua finalidade é transpor obstáculos. Assim, os aspectos relacionados ao seu estado de conservação, segurança e durabilidade são fundamentais. No entanto, como as demais estruturas, as OAE's são submetidas à degradação ao longo do tempo por diversos fatores, o que torna essencial o monitoramento das mesmas. Este trabalho tem como objetivo, entender como as inspeções cadastrais e rotineiras impactam na vida útil da OAE e como realizá-las. Analisando-se os principais fenômenos de incidência das patologias e modelos de inspeção utilizados pelo DNIT (2004), ABECE (2005) e NBR 9452 (ABNT; 2019) tornou-se possível desenvolver e propor um método de inspeção para pontes de pequeno e médio porte. Através dos indicadores, foram propostos modelos de checklist para realização das inspeções cadastrais e rotineiras, e um sistema simplificado em software Excel para gerenciamento das pontes. Esta metodologia foi validada, através de um estudo de caso real, mostrando-se eficaz para as obras de arte de pequeno e médio porte. A proposta buscou viabilizar um método simples, de baixo custo e fácil execução que disponha autonomia aos órgãos responsáveis para realizar tais vistorias, visando a conservação da estrutura e segurança dos usuários. É preciso evitar que as pontes atinjam um nível precário de desempenho e coloquem em risco a segurança de seus usuários e/ou precise de intervenções onerosas.

Palavras-chave: pontes, patologias, manutenção preventiva.

\section{ABSTRACT}

Bridges are structures that compose the road system and it's purpose is to overcome obstacles. Thus, the aspects related to its state of conservation, safety and durability are fundamental. However, such as other structures, the bridges are submitted to degradation by several factors, which makes bridge monitoring essential. This research aims to understand how the registration and routine inspections affects the lifespan of the bridges and how to perform them. By analyzing the main pathology incidence phenomena and inspection models used by DNIT (2004), ABECE (2005) and NBR 9452 (ABNT; 2019), it became possible to develop and propose an inspection method for small and medium bridges. Through the indicators, checklist models were proposed to perform the registration and routine inspections, and a simplified system in Excel software for bridge management was also proposed. This methodology was validated through a real case study, and it has prov to be effective for small and medium bridges management. The proposed methodology is friendly useful cheap and easy to implement. It provides autonomy to the responsible agencies to perform technical surveys, with the aim of the structure conservation and safety. These structures must be prevented from reaching a poor level of performance and endangering the safety of their users and/or requiring costly interventions.

Keywords: bridges, pathology, preventive maintenance. 


\section{INTRODUÇÃO}

As pontes também chamadas de Obras de Arte Especiais (OAE), são estruturas caracterizadas por sua arquitetura única, que se torna parte da composição de uma paisagem natural ou urbana. Como as demais estruturas, as pontes também se submetem à degradação ao longo do tempo por diversos fatores. Devido esse fato, podem surgir manifestações patológicas distintas que devem ser observadas e estudadas para determinação de um diagnóstico de sua origem.

O estudo preventivo pode auxiliar o desenvolvimento de técnicas, a fim de evitar problemas e certificar não somente a estabilidade da estrutura, como também a segurança das pessoas. $\mathrm{O}$ objetivo geral deste trabalho foi entender como as inspeções cadastrais e rotineiras impactam na vida útil de uma OAE e como realizá-las.

\subsection{Pontes}

São estruturas destinadas à transposição de obstáculos, tais como: rios, braços de mar, vales profundos, etc. dando continuidade a uma via (PFEIL, 1979). São constituídas por três partes principais: infraestrutura, mesoestrutura e superestrutura. Os elementos constituintes de uma ponte são ilustrados na Figura 1 (PEREIRA E SCOLARO, 2017).

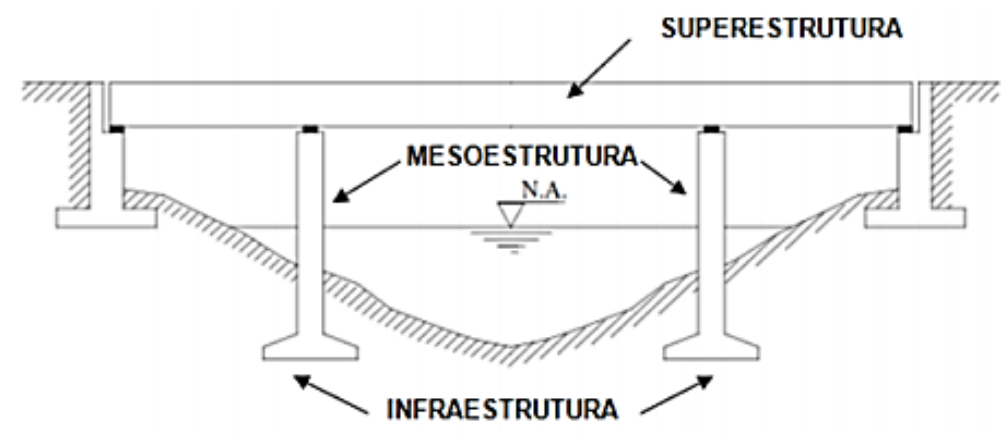

Figura 1: Elementos de uma ponte

A infraestrutura tem a função de transmitir os esforços para o terreno (MARCHETTI, 2018). A mesoestrutura é o elemento que recebe esforços da superestrutura e transmite à infraestrutura. A superestrutura é composta por lajes e vigas. É a parte útil da ponte, o elemento de suporte imediato do estrado de acordo com sua finalidade (PFEIL, 1979).

Os principais requisitos de uma ponte são: funcionalidade, segurança, estética, economia e durabilidade. As OAE's podem ser classificadas de diversas formas, com diferentes critérios, de acordo com vários autores. (MARCHETTI, 2018). Para engenharia, as classificações mais relevantes são: quanto ao material, tipo estrutural, natureza do tráfego e modelo construtivo. (SARTORTI, 2008).

As construções de pontes modernas possibilitam a utilização de diversos materiais. Porém, os mais utilizados são o concreto e o aço. Sendo que as vigas mistas são dadas pela junção dos mesmos. E são utilizadas principalmente em pontes de pequeno e médio porte (PINHO E BELLEI, 2007).

\subsection{Manifestações Patológicas}

O conhecimento sobre estruturas e materiais, baseou-se em estudos e análises dos erros anteriores, que são resultados de deteriorações precoces ou acidentes. Dessa forma, um novo tipo de estudo é explorado na engenharia: patologias. Sendo este o campo que estuda origem, formas de manifestação, consequências e mecanismos de ocorrência das falhas e dos sistemas de degradação das estruturas. (SOUZA e RIPPER, 1998).

\subsubsection{Manifestações Patológicas em pontes de concreto}

Devido às propriedades características do material e ao ambiente em que se é exposto, o concreto possui natureza instável com o passar do tempo. Outros fatores podem influenciar no seu comportamento final, sendo os mais relevantes: qualidade dos materiais, fator água cimento, execução e meio ambiente (SARTORTI, 2008). 
As causas das deteriorações podem ser expressas em dois grupos: causas intrínsecas e causas extrínsecas. As causas intrínsecas são inerentes à própria estrutura, pode ter sua origem: nos materiais e peças estruturais durante a fase de execução, por falta de manutenções, por questões próprias ao material e por ações naturais, acidentes inclusive. As causas extrínsecas estão relacionas diretamente com sua composição ou com as falhas humanas durante o projeto e utilização, e ações biológicas, físicas, mecânicas e químicas. (SOUZA e RIPPER, 1998).

Pode-se considerar como principais patologias nas pontes, os itens apresentados na Tabela 1 (VITÓRIO, 2015).

Tabela 1 - Principais manifestações patológicas das pontes rodoviárias

\begin{tabular}{|c|c|}
\hline Elemento Constituinte & Patologias Associadas \\
\hline Superestrutura & $\begin{array}{l}\text { Carbonatação; } \\
\text { Deformações nas lajes; } \\
\text { Deformações nas vigas principais; } \\
\text { Desplacamento do concreto das lajes do tabuleiro; } \\
\text { Desplacamento do concreto das transversinas; } \\
\text { Desplacamento do concreto das vigas principais; } \\
\text { Eflorescências; } \\
\text { Fissuras e/ou esmagamento de dente Gerber; } \\
\text { Fissuras nas lajes do tabuleiro; } \\
\text { Fissuras nas transversinas; } \\
\text { Fissuras nas vigas principais; } \\
\text { Oxidação de armaduras das lajes do tabuleiro; } \\
\text { Oxidação de armaduras das transversinas; } \\
\text { Oxidação de armaduras das vigas principais. }\end{array}$ \\
\hline Mesoestrutura & $\begin{array}{l}\text { Carbonatação; } \\
\text { Deformações e/ou travamento de aparelhos de apoio; } \\
\text { Deformações em pilares e/ou encontros; } \\
\text { Desplacamento do concreto de pilares e/ou encontros; } \\
\text { Eflorescências; } \\
\text { Fissuras em pilares e/ou encontros; } \\
\text { Infiltrações causadas por deficiências de drenagem dos encontros; } \\
\text { Lixiviação do concreto de pilares e/ou encontros; } \\
\text { Oxidação de armaduras de pilares e/ou encontros. }\end{array}$ \\
\hline Infraestrutura & $\begin{array}{l}\text { Descalçamento das fundações de encontros e pilares; } \\
\text { Deterioração de concreto e oxidação de armaduras nos fustes de tubulões; } \\
\text { Deterioração do concreto de sapatas, blocos de estacas ou tubulões; } \\
\text { Erosão nas fundações de encontros e pilares; } \\
\text { Erosão nos aterros dos encontros; } \\
\text { Exposição e desconfinamento de estacas; } \\
\text { Oxidação das armaduras de sapatas, blocos de estacas e cintas; } \\
\text { Recalque de fundações de encontros e pilares. }\end{array}$ \\
\hline Componentes Diversos & $\begin{array}{l}\text { Deformação dos aterros de acesso; } \\
\text { Destruição parcial de guarda-corpos e barreiras; } \\
\text { Destruição parcial do pavimento sobre a ponte; } \\
\text { Destruição total de guarda-corpos e barreiras; } \\
\text { Deterioração do concreto, fissuras e oxidação de armaduras em guarda-rodas; } \\
\text { Obstrução e/ou destruição de buzinotes. }\end{array}$ \\
\hline
\end{tabular}

1.2.2 Manifestações Patológicas em pontes de aço

Devido às propriedades do material, pode-se dizer que a corrosão é a principal causa de colapso de estruturas de aço, pois promove a perda de seção de aço (PFEIL, 2009). A presença de agentes agressivos como cloretos, sulfatos, nitritos, óxidos de enxofre e fuligem no ambiente podem acelerar as corrosões (SARTORTI, 2008).

Outro fator relevante é a ocorrência do efeito de fadiga. Fissuras ou trincas de fadiga ocorrem em estruturas submetidas a carregamentos cíclicos como no caso de pontes. Estas variações no carregamento provocam fortes oscilações nas 
tensões que causam as fissuras e trincas (SARTORTI, 2008). Podendo ocorrer, ruptura em tensões inferiores às obtidas em ensaios estáticos, que medem a ruptura dos materiais (PFEIL, 2009).

Outro fator de interferência é o efeito térmico. Temperaturas elevadas influenciam diretamente no funcionamento das estruturas de aço, pois tendem a eliminar o limite de escoamento, reduzir a resistência a escoamento e a ruptura, assim como o módulo de elasticidade (PFEIL, 2009). A deficiência de contraventamento em estruturas de aço, pode dar origem a deslocamentos transversais, de extrema gravidade, que conduzem ao colapso por flambagem. A vibração excessiva é outro problema associado pela a deficiência de contraventamento (SARTORTI, 2008).

\subsection{Vida Útil}

De acordo com a NBR 15575: Edificações Habitacionais - Desempenho (ABNT, 2013), a vida útil (VU) é o período de tempo em que a estrutura se presta às atividades para qual foi projetada, atendendo seu nível de desempenho. É expressa em anos, para estruturas civis como as pontes o tempo é aproximadamente 100 anos (POSSAN E DEMOLINER; 2013).

A vida útil de projeto (VUP) é o tempo estimado para qual a estrutura é projetada, atendendo aos requisitos de desempenho estabelecidos na norma, supondo atendimento da manutenção periódica pois, caso contrário, a VUP pode não ser atingida (ABNT; 2013). A Figura 2 representa graficamente a relação entre o desempenho em função do tempo com e sem ações de manutenção (CÂMARA BRASILEIRA DA INDÚSTRIA DA CONSTRUÇÃO, 2013).

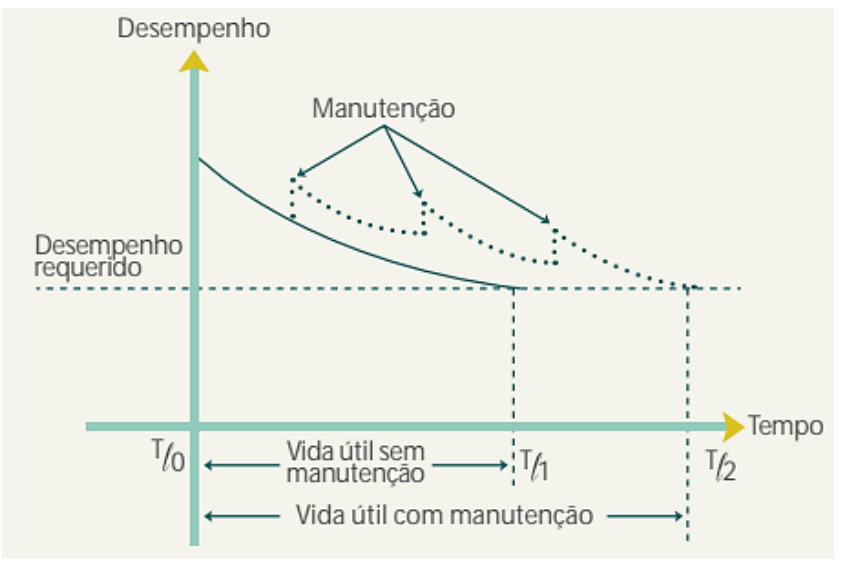

Figura 2: Influência das ações de manutenção em uma edificação

\subsection{Inspeções}

De acordo com a NBR 9452: Inspeção de pontes, viadutos e passarelas de concreto - Procedimento (ABNT, 2019) as inspeções são o conjunto de procedimentos técnicos e especializados que compreendem a coleta de dados necessários à formulação de um diagnóstico e prognóstico da estrutura, visando manter ou reestabelecer os requisitos de segurança estrutural, de funcionalidade e de durabilidade. Os tipos de inspeção e respectivas descrições estão demonstrados na Tabela 2. Baseado na NBR 9452 (ABNT; 2019).

Tabela 2 - Tipos de inspeções

\begin{tabular}{c|l}
\hline Tipo de Inspeção & \multicolumn{1}{c}{ Descrição } \\
\hline \multirow{3}{*}{ Cadastral } & $\begin{array}{l}\text { É realizada logo após a conclusão da obra e sempre que houver alterações na } \\
\text { estrutura como: alargamento, acréscimo de comprimento, reforço, mudança no } \\
\text { sistema estrutural, dentre outros. }\end{array}$ \\
\hline \multirow{5}{*}{ Especial } & $\begin{array}{l}\text { Esta inspeção apresenta mapeamento gráfico e quantitativo das anomalias dos } \\
\text { elementos aparentes e/ou acessíveis da OAE. Pode ser necessário a utilização de } \\
\text { equipamentos especiais. Deve ter uma periodicidade de cinco anos, podendo ser } \\
\text { postergada para até oito anos, dependendo do caso. }\end{array}$ \\
\hline & $\begin{array}{l}\text { Realizada devido a uma ou mais demandas não programadas, como: impactos } \\
\text { acidentais ou ações da natureza. Deve ser apresentada em relatório específico, com } \\
\text { descrição da obra e a identificação das anomalias, incluindo mapeamento, } \\
\text { documentação fotográfica e terapia indicada. }\end{array}$ \\
\hline
\end{tabular}


Inspeção de acompanhamento periódico. Visual, com ou sem a utilização de equipamentos e/ou recursos especiais para análise ou acesso, realizado em prazo não

Rotineira superior a um ano. Deve-se verificar: a evolução de anomalias já identificadas em inspeções anteriores e novas ocorrências, reparos e/ou recuperações efetuadas no período.

\subsection{Checklist}

Para Lins (2019) a ferramenta checklist ou folha de verificação, é um quadro onde há gerenciamento de dados relacionado ao número de incidências de um certo evento e sua frequência. Também pode ser usado como "folha de votação" onde os participantes após identificação e agrupamento das causas de um problema ou de alternativas para a sua solução, indiquem aquelas que pareçam ser as mais significativas.

\subsection{Escala Likert}

A escala Likert é um processo de quatro estágios em que o usuário (1) interpreta o item, (2) recupera pensamentos e sentimentos relevantes, (3) formula um julgamento baseado nestes pensamentos e sentimentos, e (4) seleciona uma reposta (TOURANGEAU E RASINSKI, 1988 apud VIEIRA E DALMORO, 2008). Os respondentes marcam somente os pontos fixos estipulados na linha, em um sistema de cinco categorias de resposta que vão de "aprovo totalmente" a “desaprovo totalmente" (VIEIRA E DALMORO, 2008). A Figura 3 apresenta o modelo de escala Likert invertida de 5 níveis. Baseado em Vieira e Dalmoro (2008).

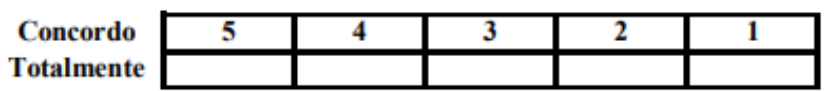

Discordo

Totalmente

Figura 3: Escala Likert com 5 pontos invertida Totalmente

Baseado em Vieira e Dalmoro (2008), a Figura 4 apresenta o modelo de escala Likert invertida de 5 níveis, utilizado.

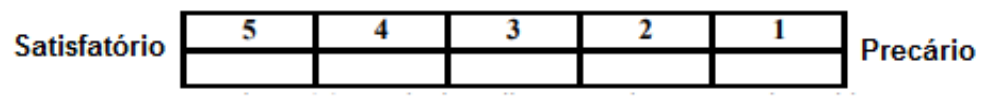

Figura 4: Escala Likert utilizada

\section{METODOLOGIA}

Os procedimentos são descritos a seguir.

\subsection{Pesquisa bibliográfica}

Através de consultas à literatura e normas vigentes, buscou-se atender aos critérios básicos para realização dos procedimentos técnicos, conforme os parâmetros exigidos. Posteriormente, realizou-se a análise das patologias de maior incidência nas pontes de concreto e aço, pois, estes se apresentam como materiais mais utilizados para construção de pontes de pequeno e médio porte no Brasil.

\subsection{Manipulação de software para elaboração da proposta}

Alvitrou-se os modelos de checklists com auxílio do software Excel, para realização de vistorias cadastrais e rotineiras. Estes checklists propõem otimizar as informações básicas necessárias. Foi baseado nos modelos preconizados pelo DNIT (2004), ABECE (2005) e NBR 9452 (ABNT; 2019).

Através da manipulação do software Excel, foi elaborado o layout organizado por seções. O software permite a impressão do checklist e desta forma, realização da coleta de dados através das inspeções em campo. O sistema de gerenciamento proposto de maneira simples, disponibiliza ao usuário:

a) banco de dados para cadastro da ponte;

b) interface interativa;

c) modelos de checklist para impressão. 


\subsection{Coleta de dados}

A fim de analisar sua viabilidade e validar a metodologia proposta, foi utilizado um estudo de caso. Os dados foram coletados em duas modalidades, sendo:

a) através de pesquisa documental junto aos órgãos responsáveis;

b) em campo, no local da ponte.

\subsubsection{Pesquisa documental}

Foram realizados os seguintes procedimentos: entrevista com o secretário de obras do município de Barão de Cocais/MG e análise dos documentos e projetos fornecidos. Foi elaborado um roteiro de perguntas direcionado à situação do munícipio em relação às inspeções de OAE’s. No dia 18 de outubro de 2019, foi realizada a entrevista.

No início das pesquisas, a Prefeitura Municipal de Barão de Cocais disponibilizou os projetos da Ponte Padre de Cruz, e fotos da estrutura durante a execução da obra. Esse material foi utilizado para analisar componentes da estrutura cujo acesso não foi possível durante a inspeção, como sua infraestrutura e aparelho de apoio.

\subsubsection{Pesquisa em campo}

Para a coleta de dados em campo, a técnica utilizada foi a vistoria in loco, que se trata da visita ao local da ponte. O objeto de estudo é a Ponte Padre Cruz localizada na Rua Padre Mauro Farias, na cidade de Barão de Cocais-MG. Esta ponte foi inaugurada em 2018.

A ponte possui $7 \mathrm{~m}$ de largura e $16 \mathrm{~m}$ de comprimento. O obstáculo de transposição é o Rio São João. Sua estrutura é composta por: encontros de concreto, vigas de aço e tabuleiro de concreto armado. Portanto, pode ser classificada como uma estrutura mista. Possui defensas de concreto. A natureza de tráfego é mista, pois transitam veículos e pedestres. A estrutura é uma obra municipal, em ambiente urbano. A Figura 5 apresenta vista superior do tabuleiro da ponte.

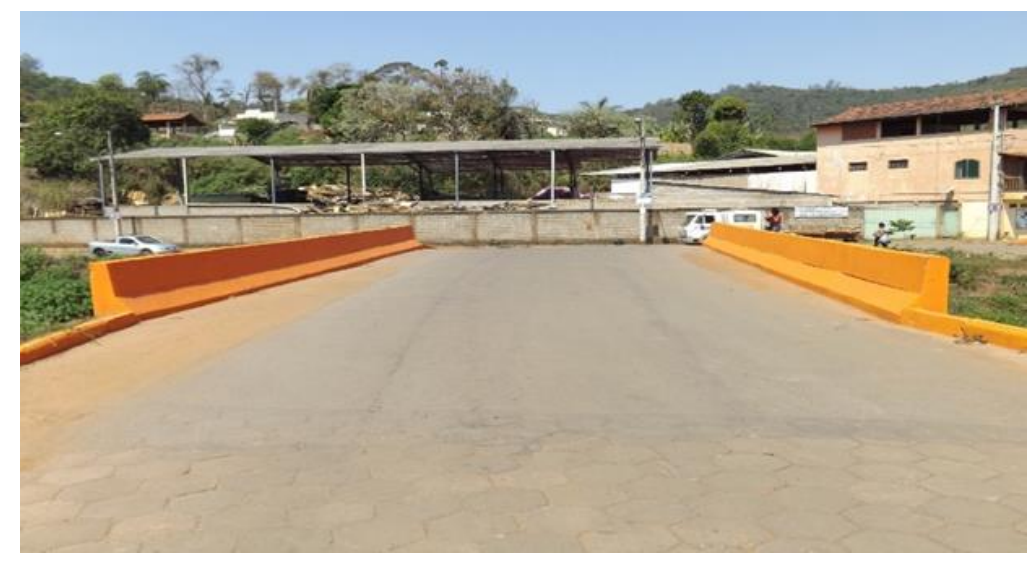

Figura 5: Parte superior do tabuleiro $1^{\mathrm{a}}$ extremidade

\section{RESULTADOS E DISCUSSÃO}

São compostos por três elementos: (1) elaboração dos checklists para inspeções cadastral e rotineira; (2) elaboração do sistema de gerenciamento e (3) visita técnica.

\subsection{Checklists de inspeção}

\subsubsection{Checklist de inspeção cadastral}

O layout do checklist foi elaborado por seções. Esta forma de organização permite agrupamento de dados análogos, facilitando a interpretação e preenchimento. Essas informações podem ser coletadas através da observação e/ou do acesso aos projetos da ponte. Totalizam 5 páginas tamanho A4. O checklist é composto por onze seções, sendo: nove para coleta de dados, uma de orientações quanto ao procedimento e uma de parâmetros orientativos. 
Tabela 3 - Resumo da ficha de inspeção rotineira

\begin{tabular}{|c|c|c|}
\hline Seção & Nome & Descrição \\
\hline 1 & Dados cadastrais & $\begin{array}{l}\text { Entrada de informações básicas associadas ao nome, localização e critérios de } \\
\text { utilização da ponte, como: situação, tráfego, tipo de obstáculo, sistema construtivo, } \\
\text { idade, dentre outros. Estes itens servirão para identificar a OAE. }\end{array}$ \\
\hline 2 & Administrativo & $\begin{array}{l}\text { Entrada de informações associadas ao início e término da obra, bem como valor total } \\
\text { investidos e responsáveis pelo projeto e construção. }\end{array}$ \\
\hline 3 & $\begin{array}{l}\text { Características } \\
\text { funcionais }\end{array}$ & $\begin{array}{l}\text { Entrada de informações associadas às características funcionais da ponte, como: } \\
\text { desenvolvimento planimétrico, pavimentação, guarda-rodas, guarda-corpo, drenagens } \\
\text { do tabuleiro, dentre outros. }\end{array}$ \\
\hline 4 & Infraestrutura & $\begin{array}{l}\text { Identificação da infraestrutura, solicita ao usuário o preenchimento quanto ao material } \\
\text { e tipo de fundação da ponte. }\end{array}$ \\
\hline 5 & Mesoestrutura & $\begin{array}{l}\text { Identificação da mesoestrutura, solicita ao usuário o preenchimento quanto ao } \\
\text { material dos pilares, a geometria, tipo de pilar e sua seção transversal. }\end{array}$ \\
\hline 6 & Superestrutura & $\begin{array}{l}\text { Identificação da superestrutura, solicita ao usuário o preenchimento quanto ao } \\
\text { material das lajes, o material das vigas, sistema estrutural, classificação do tabuleiro e } \\
\text { quantidade de transversinas. }\end{array}$ \\
\hline 7 & $\begin{array}{c}\text { Aparelhos de } \\
\text { apoio e encontros }\end{array}$ & Identificação dos aparelhos de apoio e das extremidades da ponte. \\
\hline 8 & Observações & Espaço reservado para anotações complementares. \\
\hline 9 & Outros itens & $\begin{array}{l}\text { Se refere a item adicional, a rota alternativa, para quando houver necessidade de } \\
\text { interdição da ponte. }\end{array}$ \\
\hline 10 & Instruções gerais & $\begin{array}{l}\text { Seção que orienta o usuário quanto ao procedimento de inspeção, preenchimento dos } \\
\text { itens e roteiro de registro fotográfico. }\end{array}$ \\
\hline 11 & $\begin{array}{l}\text { Parâmetros para } \\
\text { inspeção cadastral }\end{array}$ & $\begin{array}{l}\text { Se refere aos parâmetros para a inspeção cadastral, A fim de preencher corretamente } \\
\text { os itens da ficha cadastral, foram elaborados alguns tópicos como parâmetros de } \\
\text { referência. Desta forma, o usuário poderá conferir se os dados estão conforme } \\
\text { solicitados. }\end{array}$ \\
\hline
\end{tabular}

As Figuras (6 e 7) apresentam exemplo de uma seção de coleta de dados e quadro de referência, respectivamente.

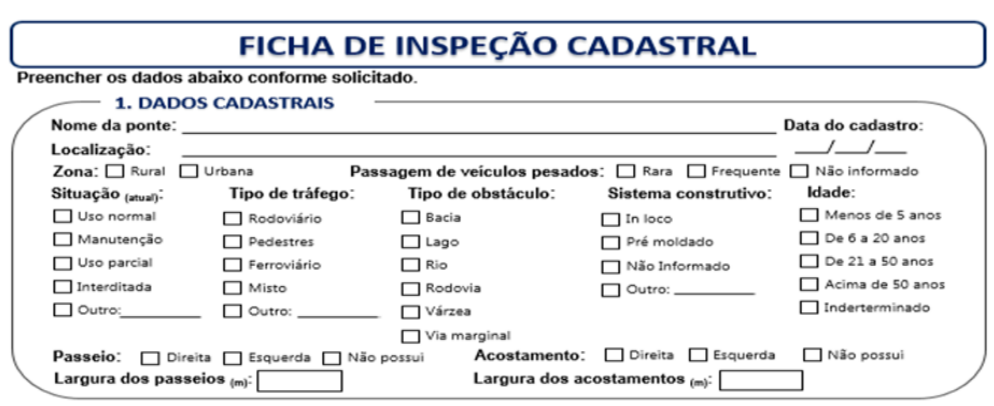

Figura 6: Seção 1 da ficha de inspeção cadastral

\begin{tabular}{|c|c|c|}
\hline Item & Descrito & Parâmetro \\
\hline Situação & Uso normal & Ponte usada nomalmente. \\
\hline Situação & Manutenção & $\begin{array}{l}\text { Ponte em manutenção (refoma, reforço, dentre } \\
\text { outros) im pedindo a passagem. }\end{array}$ \\
\hline Situação & Uso parcial & $\begin{array}{l}\text { Ponte em manutenção (reforma, reforço, dentre } \\
\text { outros) permitindo a passagem de maneira } \\
\text { controlada ou apenas pedestres. }\end{array}$ \\
\hline Situação & Interditada & Impedido qualquer tipo de trânsito. \\
\hline Tipo de tráfego & Rodoviário & Trânsito de veículos. \\
\hline Tipo de tráfego & Ferroviário & Trânsito de trens e loucomotivas. \\
\hline Tipo de tráfego & Pedestres & Trânsito de pessoas, pode ter ou não ciclovia. \\
\hline Tipo de tráfego & Misto & Trânsito de pessoas e pedestres. \\
\hline Tipo de tráfego & Outro & $\begin{array}{l}\text { Anotar outros tipos de tráfego e existência de } \\
\text { ciclovia quando for o caso. }\end{array}$ \\
\hline Sistema construtivo & In loco & $\begin{array}{l}\text { Construção da superestrutura é realizada no } \\
\text { próprio local da obra,em sua posição definifva, } \\
\text { feita sobre os pilares existentes com escoramento. }\end{array}$ \\
\hline Sistema construtivo & Pré-moldado & $\begin{array}{l}\text { É uflizado vigas pré fabricadas (aço, concreto etc.) } \\
\text { e a concretagem da laje é feita no local. }\end{array}$ \\
\hline Sistema construtivo & Outro & Anotar outro sistema construtivo se for o caso. \\
\hline
\end{tabular}

Figura 7: Quadro orientativo 


\subsubsection{Checklist de inspeção rotineira}

As inspeções rotineiras são compostas por registro fotográfico e preenchimento da ficha de inspeção (DNIT, 2004). O modelo proposto atende aos requisitos básicos da inspeção de forma simplificada e objetiva. São sete páginas tamanho A4.

Com layout organizado por seções a fim de obter uma padronização, o checklist é composto por oito seções e três subseções, sendo: cinco para atribuição de nota conforme a vistoria, três para anotações complementares, uma de orientações quanto ao procedimento e uma de parâmetros orientativos.

Tabela 4 - Resumo da ficha de inspeção rotineira

\begin{tabular}{|c|c|c|c|}
\hline Seção & Nome & Tipo de Avaliação & Descrição \\
\hline 1 & Informações & $\begin{array}{l}\text { (Anotações } \\
\text { complementares) }\end{array}$ & $\begin{array}{l}\text { Insere os dados referentes a identificação da estrutura. São estes: } \\
\text { Nome, localização e data da vistoria. }\end{array}$ \\
\hline 2.1 & $\begin{array}{l}\text { Superestrutura } \\
\text { - pista/acesso }\end{array}$ & Aspecto funcional & $\begin{array}{l}\text { Avalia os aspectos da superestrutura relacionados à pista e acesso. } \\
\text { Conforme a NBR } 9452 \text { (2019), esses itens são associados ao } \\
\text { desemprenho funcional da OAE, pois descrevem aspectos de } \\
\text { conforto, segurança e utilização do usuário bem como a finalidade } \\
\text { da ponte. Os parâmetros avaliados são: acesso à ponte, } \\
\text { acostamentos, guarda corpo, guarda rodas, irregularidades na pista, } \\
\text { juntas de dilatação, passeios, e sistema de drenagem. }\end{array}$ \\
\hline 2.2 & $\begin{array}{l}\text { Superestrutura } \\
\quad \text { - laje }\end{array}$ & Aspecto estrutural & $\begin{array}{l}\text { Avalia os aspectos da superestrutura relacionados à laje. Conforme } \\
\text { a NBR } 9452 \text { (2019), esses itens são associados ao desemprenho } \\
\text { estrutural da OAE, pois se referem à sua estabilidade e capacidade } \\
\text { portante, sob os critérios de estado limite último. Os parâmetros } \\
\text { avaliados são: armadura exposta, buracos, carbonatação, } \\
\text { cobrimento, desplacamento no concreto, eflorecência, fissuração, } \\
\text { infiltração e trincas. }\end{array}$ \\
\hline 2.3 & $\begin{array}{l}\text { Superestrutura } \\
\quad-\text { vigas }\end{array}$ & Aspecto estrutural & $\begin{array}{l}\text { Avalia os aspectos da superestrutura relacionados às vigas. Os } \\
\text { parâmetros avaliados são: armadura exposta, buracos, } \\
\text { carbonatação, cobrimento, corrosão, desplacamento no concreto, } \\
\text { eflorecência, fadiga, fissuração, infiltração e trincas. }\end{array}$ \\
\hline 3 & Mesoestrutura & Aspecto estrutural & $\begin{array}{l}\text { Avalia os aspectos relacionados a mesoestrutura. Os parâmetros } \\
\text { avaliados são: aparelhos de apoio, armadura exposta, carbonatação, } \\
\text { cobrimento, corrosão, desaprumo, deslocamento dos pilares, } \\
\text { desplacamento no concreto, eflorecência, fadiga, fissuração, } \\
\text { infiltração e trincas. }\end{array}$ \\
\hline 4 & Infraestrutura & Aspecto estrutural & $\begin{array}{l}\text { Avalia os aspectos relacionados a infraestrutura. Os parâmetros } \\
\text { avaliados são: armadura exposta, descalçamento de fundações, } \\
\text { deslocamento das fundações, deterioração do concreto, erosão, } \\
\text { estacas desenterradas e recalque. }\end{array}$ \\
\hline 5 & $\begin{array}{l}\text { Critérios de } \\
\text { pontuação }\end{array}$ & $\begin{array}{c}\text { (Anotações } \\
\text { complementares) }\end{array}$ & $\begin{array}{l}\text { Explica ao usuário como é calculado as notas técnicas atribuídas e } \\
\text { recebe a nota final. }\end{array}$ \\
\hline 6 & $\begin{array}{l}\text { Anotações } \\
\text { pertinentes }\end{array}$ & $\begin{array}{c}\text { (Anotações } \\
\text { complementares) }\end{array}$ & $\begin{array}{l}\text { Espaço reservado para anotações complementares e desenho dos } \\
\text { locais que apresentam patologias. }\end{array}$ \\
\hline 7 & $\begin{array}{l}\text { Instruções } \\
\text { gerais }\end{array}$ & $\begin{array}{l}\text { (Orientação quanto } \\
\text { ao procedimento) }\end{array}$ & $\begin{array}{l}\text { Seção que orienta o usuário quanto ao procedimento de inspeção, } \\
\text { preenchimento dos itens e roteiro de registro fotográfico. }\end{array}$ \\
\hline 8 & $\begin{array}{l}\text { Parâmetros } \\
\text { para inspeção } \\
\text { rotineira }\end{array}$ & $\begin{array}{l}\text { (Orientação quanto } \\
\text { aos parâmetros) }\end{array}$ & $\begin{array}{l}\text { São parâmetros utilizados. Compreendem itens como: estrutura } \\
\text { geral da ponte, tabela dos tipos de fissura e fluxograma para as } \\
\text { hipóteses de reconversão de estruturas com desempenho } \\
\text { insatisfatório. Também há o quadro de referência do DNIT (2004). }\end{array}$ \\
\hline
\end{tabular}

A atribuição de notas segue conforme a escala Likert. A pontuação varia de 5 (bom) a 1 (precário). Com 5 ou 3 pontos, conforme o item avaliado. As notas técnicas são calculadas da seguinte forma: 
a) nota técnica parcial: média obtida pela soma das notas de cada item avaliado do componente da ponte, dividido pela quantidade de itens avaliados. Esta nota mensura a situação de cada componente conforme a observação em vistoria.

b) nota técnica total: corresponde a menor nota obtida entre as notas parciais. Essa nota representa a situação global da estrutura, que poderá ser avaliada de acordo com o quadro de referência do DNIT (2004).

A estrutura recebe uma nota técnica total referente aos aspectos estruturais, avaliando a superestrutura, mesoestrutura e infraestrutura e uma nota técnica total referente aos aspectos funcionais, avaliados na seção 2.1 da ficha de inspeção.

As Figuras (8 e 9) apresentam exemplo de uma seção avaliada e quadro de referência do DNIT (2004), respectivamente.

\begin{tabular}{|c|c|c|c|c|c|}
\hline ITENS AVALIADOS: & NOTA 5 & NOTA 4 & NOTA 3 & NOTA 2 & NOTA 1 \\
\hline 2.1.1. Acesso à ponte & $\Gamma_{\text {Bom/Fácil acesso }}$ & $\Gamma_{\text {Regular }}$ & $\Gamma$ Comprometido & $\Gamma_{\text {Ruim }}$ & $\Gamma$ Inacessivel \\
\hline 2.1.2. Irregularidades na pista & ГNão há & $\Gamma$ Leve & $\Gamma$ Moderada & $\Gamma_{\text {Intensa }}$ & ГIntransitável \\
\hline 2.1.3. Acostamentos & $\Gamma_{\text {Bom }}$ & & $\Gamma_{\text {Ruim }}$ & & $\Gamma_{\text {Não possui }}$ \\
\hline 2.1.4. Guarda-corpo & $\Gamma_{\text {Bom }}$ & & ГRuim & & ГNão possui \\
\hline 2.1.5. Guarda-roda & $\Gamma$ Bom & & $\Gamma$ Ruim & & $\Gamma_{\text {Nà̃o possui }}$ \\
\hline 2.1.6. Juntas de dilatação & $\Gamma_{\text {Bom/Em uso }}$ & & $\Gamma_{\text {Ruim/Inoperante }}$ & & $\Gamma_{\text {Não possui }}$ \\
\hline 2.1.7. Passeios & $\Gamma_{\text {Bom }}$ & & $\Gamma_{\text {Ruim }}$ & & $\Gamma_{\text {Não possui }}$ \\
\hline 2.1.8. Sistema de drenagem & $\Gamma_{\text {Bom/Em uso }}$ & & $\Gamma_{\text {Ruim/Inoperante }}$ & & $\Gamma_{\text {Não possui }}$ \\
\hline NOTA TÉCNICA PARCIAL: & \multicolumn{5}{|c|}{ 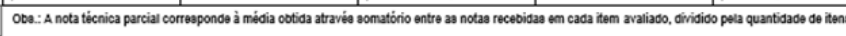 } \\
\hline
\end{tabular}

Figura 8: Seção 2.1 da ficha de inspeção rotineira

\begin{tabular}{|c|c|c|c|c|}
\hline Nota & $\begin{array}{c}\text { Dano no elemento / Insuficiência } \\
\text { estrutural }\end{array}$ & Ação corretiva & $\begin{array}{l}\text { Condiçōes de } \\
\text { estabilidade }\end{array}$ & Classificação das condiçōes da ponte \\
\hline 5 & Não há danos ou insuficiência estrutural. & Nada a fazer. & Boa & Obra sem problemas. \\
\hline 4 & $\begin{array}{l}\text { Há alguns danos mas não há sinais de } \\
\text { estejam gerando insuficiência estrutural. }\end{array}$ & $\begin{array}{l}\text { Nada a fazer, apenas serviços } \\
\text { de manutenção. }\end{array}$ & Regular & Obra sem problemas importantes. \\
\hline 3 & $\begin{array}{l}\text { Há danos gerando algum ipo de } \\
\text { insuficiência estrutural, mas não há sinais de } \\
\text { comprometimento da estabilidade da obra. }\end{array}$ & $\begin{array}{l}\text { A recuperação da obra pode ser } \\
\text { postergada, devendo-se porém, } \\
\text { neste caso, colocar o problema } \\
\text { em observação sistemáfca. }\end{array}$ & Ruim & $\begin{array}{l}\text { Obra potencialmente problemática. Recomenda- } \\
\text { se acompanhar a evolução dos problemas através de } \\
\text { inspeçōes rofineiras, para detectar em tempo hábil,um } \\
\text { eventual agravamento da insuficiência estrutural. }\end{array}$ \\
\hline 2 & $\begin{array}{l}\text { Há danos gerando significafva insufciência } \\
\text { estrutural na ponte, porém, não há ainda, } \\
\text { aparentemente um risco tangivel de colapso } \\
\text { estrutural. }\end{array}$ & $\begin{array}{l}\text { A recuperação (geralmente com } \\
\text { reforço estrutural) da obra deve } \\
\text { ser fetta a curto prazo. }\end{array}$ & Sofrível & $\begin{array}{l}\text { Obra problemática. Postergar demais a } \\
\text { recuperação da obra pode levá-la a um estado } \\
\text { críico, implicando também sério compromeimento da } \\
\text { vida úsil da estrutura. Inspeções intermediárias }{ }^{1} \text { são } \\
\text { recomendáveis para monitorar os problemas. }\end{array}$ \\
\hline 1 & $\begin{array}{l}\text { Há danos gerando grave insuficiência } \\
\text { estrutural na ponte, o elemento em questão } \\
\text { encontra-se em estado críco. Existe risco } \\
\text { tangivel de colapso estrutural. }\end{array}$ & $\begin{array}{l}\text { A recuperação (geralmente com } \\
\text { reforço estrutural) ou em alguns } \\
\text { casos, substituição da obra deve } \\
\text { ser fełta sem tardar. }\end{array}$ & Precária & $\begin{array}{l}\text { Obra crítica. Em alguns casos, pode configuraruma } \\
\text { situação de emergência podendo a recuperação da } \\
\text { obra ser acompanhada de medidas preventivas } \\
\text { especiais,tais como: restriçöes de carga na ponte, } \\
\text { interdição parcial ou total do tráfego, escoramentos } \\
\text { provisórios, instrumentação de leturas conínuas, } \\
\text { dentre outros. }\end{array}$ \\
\hline
\end{tabular}

Figura 9: Seção 2.1 da ficha de inspeção rotineira

\subsection{Sistema de gerenciamento}

Elaborado no software Excel, os objetivos gerais são: cadastro de dados da OAE e disponibilizar impressão das fichas de inspeção. A ideia central é permitir ao usuário realizar tratamento dos dados, a fim de organizar como um banco de dados os itens coletados em campo. Para elaboração deste sistema, foram criadas quatro telas principais de interação e uma planilha de banco de dados. A Figura 10 apresenta suas interfaces. 
a) Tela inicial

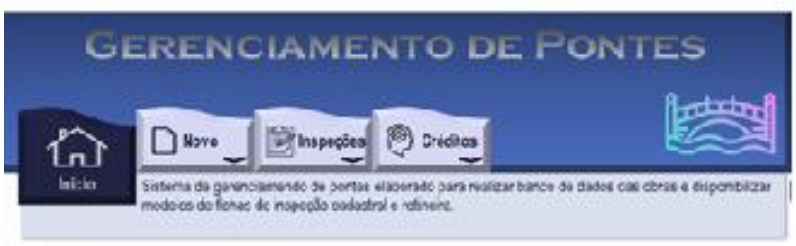

\section{Seja trem vinda (a)!}

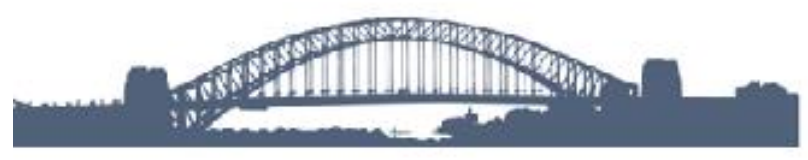

c) Tela "Inspeções"

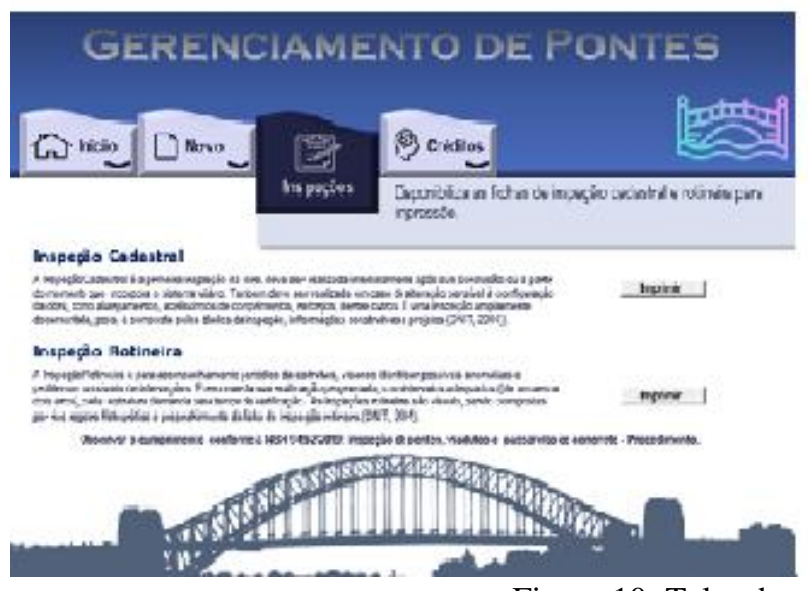

b) Tela "Novo"

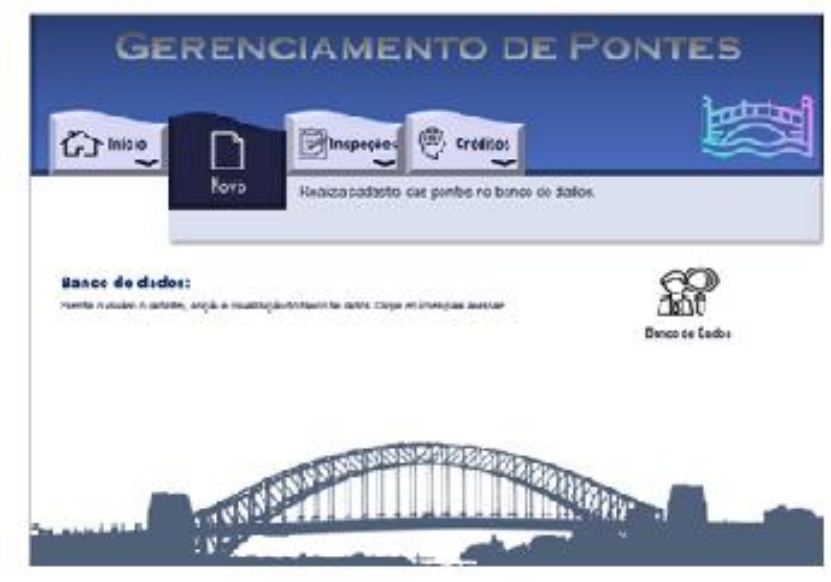

d) Tela "Créditos"

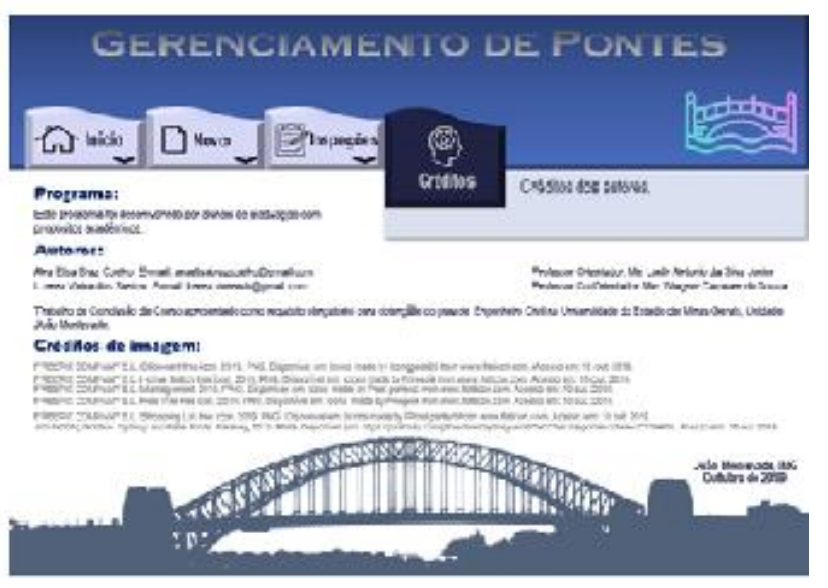

Figura 10: Telas do sistema de gerenciamento

A Tabela 5 apresenta as atribuições de cada uma das telas do sistema de gerenciamento proposto.

Tabela 5 - Telas do sistema de gerenciamento

\begin{tabular}{c|l}
\hline Tela & \multicolumn{1}{c}{ Descrição } \\
\hline Inicial & $\begin{array}{l}\text { Trata-se do início do sistema. É composta por uma mensagem de boas-vindas } \\
\text { e quatro botões, sendo eles: Início, Novo, Inspeções e Créditos }\end{array}$ \\
\hline Novo & $\begin{array}{l}\text { Seção que permite o acesso ao banco de dados. É composta por um botão, ao } \\
\text { clicar neste botão, através de hiperlink o usuário é encaminhado para a } \\
\text { planilha onde poderá cadastrar, editar ou visualizar as pontes cadastradas. }\end{array}$ \\
\hline Inspeções & $\begin{array}{l}\text { Seção que permite a impressão das fichas de inspeção. É composta por dois } \\
\text { botões, onde o usuário inicia o comando de impressão ao clicar. Esta parte foi } \\
\text { viabilizada por programação no próprio Excel, através do uso de macros. Há } \\
\text { dois textos breves descritivos de cada inspeção, para melhor esclarecimento. }\end{array}$ \\
\hline Créditos & $\begin{array}{l}\text { Refere-se às referências de desenvolvimento do sistema, quanto aos autores e } \\
\text { o vínculo como proposta desenvolvida de forma acadêmica. }\end{array}$ \\
\hline
\end{tabular}

\subsection{Visita técnica}

Foi realizada a vistoria in loco na Ponte Padre Cruz, na cidade de Barão de Cocais-MG. Primeiramente, foi feita a inspeção cadastral e em seguida, a inspeção rotineira, ambas na mesma data, 18 de Outubro de 2019. Foram coletados registros fotográficos para identificação das condições atuais da ponte e demonstração dos resultados. 
Com base nas observações que foram possíveis, neste momento, a ponte não apresenta danos que comprometam sua estrutura. Porém, observa-se que algumas regiões requerem atenção e possíveis manutenções no contexto preventivo, principalmente no que se refere ao seu desempenho funcional.

As percepções mais notáveis são:

a) é necessário a realização periódica de limpeza das vegetações nos arredores da ponte;

b) é necessário realizar o acabamento nas laterais superior do tabuleiro, removendo os arames de amarração, a fim de evitar possível oxidação e abertura de fissuras, no futuro.

c) é recomendada a pintura antioxidante nas vigas da laje inferior (longarinas e transversinas) pois, devido ao material constituinte, estas são sujeitas à oxidação ocasionada por muitos fatores, neste caso, a possível incidência de umidade natural proveniente do rio;

d) não há passeios ou guarda corpo na ponte, o que compromete a segurança dos pedestres, visto que está localizada em ambiente urbano;

e) não há sinalizações horizontais na pista ou placas de identificação da ponte.

As Figuras (11 e 12) apresentam os itens destacados nas principais percepções.

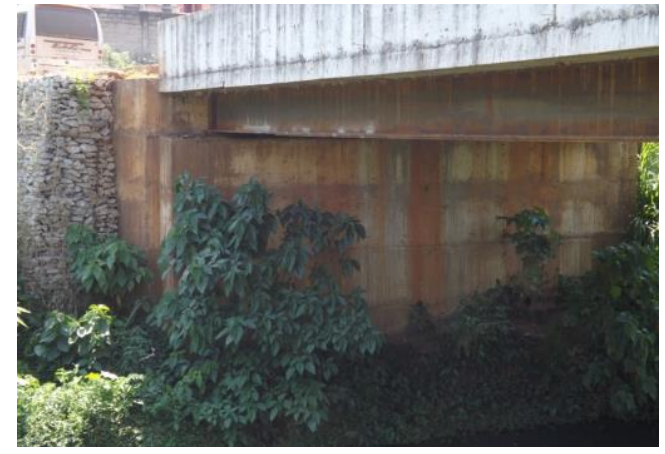

Figura 11: Encontro visto da lateral esquerda

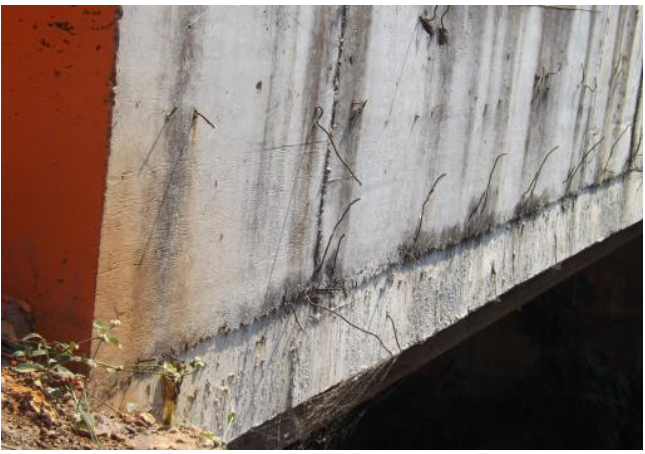

Figura 12: Defensas visto da lateral direita

Dos resultados obtidos, pode-se realizar as seguintes considerações:

a) na inspeção cadastral, foram anotadas as informações solicitadas e decorreu como previsto. Estes dados foram obtidos através dos projetos e da inspeção in loco.

b) na inspeção rotineira, de acordo com a classificação de notas atribuídas, a nota técnica total foi: 5 para aspectos estruturais, caracterizando "Boa: obra sem problemas" e 3,5 para aspectos funcionais, classificando como "Ruim: obra potencialmente problemática" de acordo como a Figura 9. A pontuação baixa obtida foi no item 2.1 do checklist, e está associada às características funcionais, conforme descrito anteriormente.

\section{CONSIDERAÇÕS FINAIS}

Fatores como a falta de manutenções periódicas podem agravar a presença de manifestações patológicas, contribuindo para que a estrutura atinja estado crítico de conservação. A vida útil de uma OAE inclui o constante monitoramento para sua preservação. Desta forma, para atendimento dos requisitos de desempenho, a realização de inspeções são fundamentais pois impactam de forma direta na vida útil da ponte.

A metodologia sugerida, é um sistema de gerenciamento de pontes simplificado. Composto por checklists de inspeções cadastrais, rotineiras e banco de dados. Trata-se de um instrumento de fácil acesso, manuseio e baixo custo. Os dados coletados na inspeção cadastral alimentam o banco de dados, delineando a tipologia da estrutura. Através da inspeção rotineira, é realizado o monitoramento do estado de conservação da ponte, os dados coletados tornam-se informações que servem como indicadores para a necessidade ou não de intervenções.

Neste contexto de estudo de profilaxia, este trabalho sugere uma metodologia que pode ser replicada em outras pontes sem maiores dificuldades, contribuindo para sua preservação. Pode-se concluir que a proposta se demonstra válida, viável e eficaz para pontes de pequeno e médio porte. 


\section{REFERÊNCIAS}

ASSOCIAÇÃO BRASILEIRA DE NORMAS TÉCNICAS. NBR 15.575: Edificações habitacionais - Desempenho. Parte 1. Rio de Janeiro, 2013.

ASSOCIAÇÃO BRASILEIRA DE NORMAS TÉCNICAS. NBR 9452: Inspeção de pontes, viadutos e passarelas de concreto - Procedimento. Rio de Janeiro, 2016.

CÂMARA BRASILEIRA DA INDUSTRIA DA CONSTRUÇÃO - CBIC. Guia Orientativo para Atendimento à Norma ABNT NBR 15575/2013. Brasília: Gadioli Cipolla Comunicação, 2013. Disponível em: https://site.abece.com.br/download/pdf/130626CBICGuiaNBR2EdicaoVersaoWeb.pdf. Acesso em: 19 jun. 2019.

PROJETOS. Prefeitura Municipal de Barão de Cocais. Projeto Ponte Padre Cruz. 2018.

LINS, Bernardo F. E. Ferramentas básicas da qualidade. Ciência da Informação, Brasília-DF, ano 2, v. 48, p. 152161, 19 fev. 2019. Disponível em: http://revista.ibict.br/ciinf/article/view/502/502. Acesso em: 12 set. 2019.

MARCHETTI, Osvaldemar. Classificação das pontes. In: MARCHETTI, Osvaldemar. Pontes de Concreto Armado. São Paulo - SP: Edgard Blücher Ltda., 2018. 246 p.

PEREIRA, Luiz Eduardo; SCOLARO, Taylana Piccinini. Referencial bibliográfico: Elementos de pontes. In: PEREIRA, Luiz Eduardo; SCOLARO, Taylana Piccinini. Análise comparativa entre projetos de pontes de diferentes materiais com vistas à construção sustentável. Orientador: Prof. Msc. Jairo Trombetta. 2017. Trabalho de Conclusão de Curso (Engenharia Civil) - Universidade Tecnológica Federal do Parará, Pato Branco, 2017. f. 95. Disponível em: http://repositorio.roca.utfpr.edu.br/jspui/bitstream/1/10280/1/PB_COECI_2017_2_42.pdf. Acesso em: 11 set. 2019.

PFEIL, Walter. Conceitos Gerais - Classificação. In: PFEIL, Walter. Pontes em concreto armado. Rio de Janeiro - RJ: Livros Técnicos e Científicos Editora S.A., 1979.

PFEIL, Walter; PFEIL, Michèle. Estruturas de Aço Dimensionamento Prático. Rio de Janeiro: LTC -Livros Técnicos e Científicos Editora Ltda., 2009.

PINHO, Fernando Ottoboni; BELLEI, Ildony Hélio. Pontes e Viadutos em Vigas Mistas. Rio de Janeiro: Instituto Brasileiro de Siderurgia, 2007.

POSSAN, Edna; DEMOLINER, Carlos Alberto. Desempenho, durabilidade e vida útil das edificações: abordagem geral. Revista Técnico-Científica do CREA-PR, [S. 1.], 1 out. 2013. Disponível em: http://creaprw16.creapr.org.br/revista/Sistema/index.php/revista/article/viewFile/14/10. Acesso em: 24 abr. 2019.

SARTORTI, Artur Lenz. Identificação de patologias em pontes de vias urbanas e rurais no município de Campinas-SP. 2008. Dissertação (Mestrado, Engenharia Civil) - Universidade Estadual de Campinas, Campinas - SP, 2008. Disponível em: http://repositorio.unicamp.br/bitstream/REPOSIP/257673/1/Sartorti_ArturLenz_M.pdf. Acesso em: 24 abr. 2019.

SOUZA, Vicente Custódio Moreira de; RIPPER, Thomaz. Patologia, recuperação e reforço de estruturas de concreto. São Paulo - SP: Editora Pini Ltda., 1998.

VIEIRA, Kelmara Mendes; DALMORO, Marlon. Dilemas na Construção de Escalas Tipo Likert: o Número de Itens e a Disposição Influenciam nos Resultados?. XXXII Encontro da ANPAD, Rio de Janeiro, p. 1-16, 10 set. 2008. Disponível em: http://www.anpad.org.br/admin/pdf/EPQ-A1615.pdf. Acesso em: 30 out. 2019. 